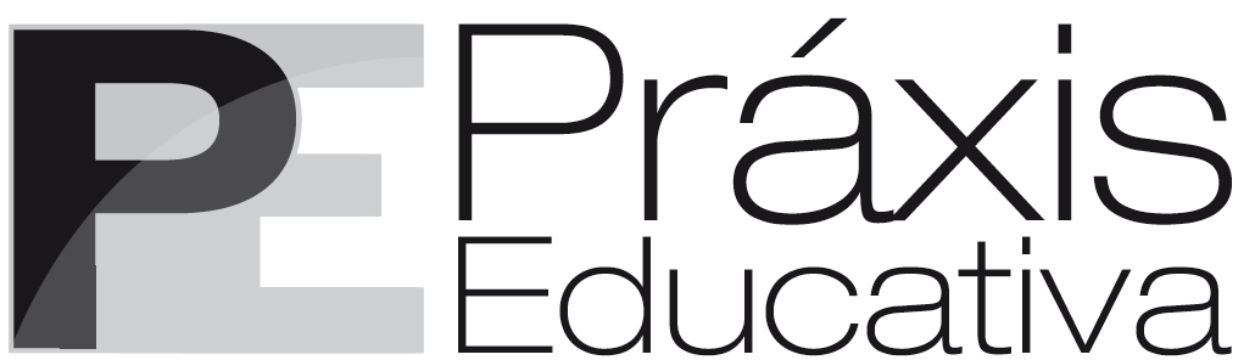

ISSN 1809-4309 (Versão online) DOI: 10.5212/PraxEduc.v.11i2.0012

\title{
OLIVEIRA, Margarida Maria Dias de; COSTA, Aryana (Orgs.). Para que(m) se avalia? Livros Didáticos e Avaliações (Brasil, Chile, Espanha, Japão, México e Portugal). Natal: EDUFRN, 2014. 164 p.
}

Juliana Gelbcke*

Para que(m) se avalia? Essa é a provocação que encontramos já na capa do livro que, curiosamente, possui o formato de um manual didático, organizado pela professora Margarida Maria Dias de Oliveira, do Departamento de História da Universidade Federal do Rio Grande do Norte (UFRN), também representante de História na Comissão Técnica do Programa Nacional do Livro Didático (PNLD) nas avaliações de 2007, 2008, 2010, 2011, 2013 e 2014; e pela professora do Departamento de História da Universidade do Estado do Rio Grande do Norte (UERN), Aryana Costa. As autoras têm em comum as preocupações e os desafios que envolvem o ensino de História. A coletânea composta por seis capítulos explora o processo de seleção, de avaliação, de distribuição e usos do livro didático por professores e alunos em seis países: Brasil, Chile, Espanha, Japão, México e Portugal. Dessa forma, o livro é estruturado em duas partes compostas pelos mesmos artigos, mas disponíveis em dois idiomas: português e espanhol, visando, assim, disponibilizar os textos nos idiomas originais de seus autores, possibilitando maior divulgação desse intercâmbio de experiências.

Pensar o livro didático significa abrir um leque de possibilidades de análise. De acordo com Oliveira e Costa, de pesquisas voltadas a uma análise ideológica dos livros didáticos, iniciadas em meados dos anos de 1970, enveredamos por problemáticas que passaram a levar em consideração, por exemplo, a relação dos livros didáticos com o mercado editorial, o processo de seleção e a utilização por professores e alunos, a análise sobre os exercícios, os elementos iconográficos e os conteúdos presentes no livro, assim como a relação entre o livro didático e as políticas públicas envolvidas no processo de sua elaboração, de sua seleção, de sua distribuição e de sua circulação, que também é uma das principais preocupações desta coletânea. Segundo as autoras, o PNLD, “[...] pelo seu tamanho e impacto, recorrentemente aparece nesses estudos, fomentando diferentes posicionamentos, dentre os quais alguns destacam o descompasso entre a avaliação dos livros pelo Programa e aquela realizada pelos professores em sala de aula" (p. 8-9).

Assim sendo, Para que(m) se avalia? Livros Didáticos e Avaliações tem o objetivo de "[...] contribuir para o aprofundamento das discussões sobre o processo de avaliação do livro didático de História no Brasil" (p. 9). Procurando analisar como outras sociedades também pensam suas políticas públicas para a educação e, mais especificamente, as políticas de avaliação e distribuição

${ }^{*}$ Mestranda do PPGE/UEPG. Bolsista da CAPES. E-mail: <juliana.gelbcke@yahoo.com.br>.

Práxis Educativa, Ponta Grossa, v. 11, n. 2, p. 526-530, maio/ago. 2016 Disponível em: < http://www.revistas2.uepg.br/index.php/praxiseducativa > 
de materiais didáticos, o livro fornece uma troca de experiências por meio de um estudo comparativo que se mostra bastante válido na medida em que, nas palavras das apresentadoras, possibilita "[...] colocarmos nossa própria história em perspectiva, redimensionando nossos problemas ou reafirmando decisões e posicionamentos" (p. 9).

No primeiro capítulo, Programa Nacional do Livro Didático - PNLD: processo de uma política e possibilidade de aperfeiçoamento, Itamar Freitas e Margarida Maria Dias de Oliveira narram as etapas do processo de avaliação pedagógica dos manuais didáticos pelo PNLD no Brasil. Embasados na experiência que tiveram como integrantes do Programa, os autores explicitam as várias fases da avaliação a que uma mesma obra é submetida, destacando que são utilizados os mesmos critérios, os quais são de conhecimento prévio dos autores e/ou detentores dos direitos autorais, para todas as obras. Dessa forma, uma mesma coleção é cuidadosamente avaliada por diferentes sujeitos, garantindo, assim, revisão constante, no sentido de minimizar eventuais equívocos, conforme os autores explicitam.

A partir das etapas desse processo, Freitas e Oliveira destacam alguns desafios a superar na avaliação pública brasileira, levantando duas questões que, juntas, ajudam a responder a pergunta que subjaz a segunda parte do artigo: "[...] em que medida a avaliação promovida pelo PNLD pode ser aperfeiçoada?” (p. 15). A primeira delas, segundo os autores, tem relação com questões apontadas no documento Recomendações para uma política pública de livros didáticos, resultado do primeiro grande momento de avaliação do PNLD por autores e editores de livros didáticos, representantes de secretarias estaduais e municipais de educação, professores da Educação Básica, professores universitários e envolvidos com a formação de docentes e pesquisadores de ensino. Desse documento, Freitas e Oliveira chamam a atenção para duas preocupações destacadas pelos autores do documento, as quais serão discutidas ao longo do capítulo: a "cristalização de uma concepção de livro didático" e o "descompasso entre a expectativa do PNLD e a dos docentes". A segunda questão tem a ver com os desafios enfrentados pelos próprios autores na condução de parte da política de avaliação nos últimos dez anos e "[...] diz respeito à abordagem da produção acadêmica na construção dos editais e instrumentos diretos de avaliação e o processo de capacitação dos avaliadores” (p. 16).

Sobre a cristalização de uma concepção de livro didático, Freitas e Oliveira destacam que, na época que essa questão foi levantada, o modelo de livro didático instaurado "[...] estruturava o trabalho na sala de aula, motivando muito pouco a iniciativa e a autonomia do professor" (p. 17). Dessa forma, o documento recomendava que o PNLD acolhesse novas propostas que destoassem do modelo cristalizado de livro didático. Assim sendo, os autores fazem uma breve análise de alguns pontos dos livros didáticos, como, por exemplo, dos conteúdos substantivos, seleção dos conteúdos, arquitetura da informação, dentre outros elementos, para ver se essas recomendações foram ou não acatadas. No entanto, os pesquisadores percebem que houve poucas mudanças, ou seja, a maior parte das recomendações sugeridas acabaram não sendo adotadas pelos autores e editores. Dessa forma, observa-se que se instaurou uma espécie de "modelo padrão" a ser seguido, o que fez com que, mesmo tendo várias opções de coleção de livros didáticos, elas acabam sendo muito parecidas, tanto em seus formatos quanto na seleção e na abordagem que fazem dos conteúdos. Por outro lado, os autores destacam algumas mudanças significativas com relação ao manual do professor, tais como a ampliação do espaço para orientação do livro do aluno para além das respostas - questões-chave para o ensino também foram incluídas, dentre outras. No entanto, eles também observaram que, ao exemplo do que acontece com o livro do aluno, uma "cristalização" já toma conta desses exemplares. Segundo os autores, "[...] os tópicos sobre ideia de história, aprendizagem, metodologia, avaliação começam a assemelhar-se de uma coleção para a outra e a questão da progressão das aprendizagens [...] sequer tem sido ensaiada" (p. 19).

Práxis Educativa, Ponta Grossa, v. 11, n. 2, p. 526-530, maio/ago. 2016 Disponível em: <http://www.revistas2.uepg.br/index.php/praxiseducativa $>$ 
Freitas e Oliveira afirmam que o descompasso entre as expectativas do PNLD e a dos docentes da escolarização básica permanecem ainda hoje, e, com relação a isso, fazem uma breve avaliação dos motivos que levam a essas diferenças de expectativas. Entre elas, os autores citam a falta de pesquisas que tenham o ensino de História e o livro didático de História como questão principal. Eles também alegam haver uma falta dessas preocupações na formação inicial dos docentes, mas também ressaltam que programas como o PIBID e o PROFHISTÓRIA vêm trazendo mudanças nesse contexto, aumentando o número, dentro de quatro/cinco anos, de pesquisadores preocupados com o ensino de História. Para os autores, “[...] é provável que daí surja uma atitude mais favorável ao livro didático como assunto estratégico nos cursos de formação inicial” (p. 20). Uma das saídas apontadas por Freitas e Oliveira para esses problemas é a "[...] transformação do livro didático em objeto estratégico de exame nos cursos de licenciatura e de pós-graduação em história. [...]. Outra possibilidade é ampliar, ainda mais, a participação de professores da escola básica nas equipes de avaliação do PNLD” (p. 22).

Os autores finalizam fazendo um convite ao leitor para refletir sobre alguns pontos, como a relação Estado $v$ s. mercado editorial; a relação que professores, alunos e familiares mantêm com os livros, as relações edital $v$ s. livro didático e livro didático $v$ s. currículos praticados, dentre uma série de outras questões que, se exploradas mais a fundo, somando-se à ampliação do investimento da pesquisa histórica na área do ensino, podem contribuir para fazer um livro didático de História cada vez melhor.

Em Livros didáticos, seu processo de avaliação e uso na educação básica: Chile, Espanha e Japão, Laura Lima Muñiz e María del Refugio Plazola Díaz realizam uma breve análise descritiva comparando o processo de avaliação, de seleção e de distribuição de livros didáticos nos três países. As autoras destacam, por exemplo, a participação dos professores e dos alunos, o tempo de uso desses materiais, a relação com as editoras, a relação entre livro didático e currículo, dentre outros elementos. A partir desse relato das etapas de avaliação e de seleção dos livros didáticos, observa-se alguns pontos em comum entre os três países, como, por exemplo, o fato de que tanto no Chile quanto na Espanha e no Japão os livros didáticos são gratuitos e distribuídos a todos os alunos. No entanto, no Japão, eles também são obrigatórios e distribuídos gratuitamente inclusive para as escolas privadas. Já, na Espanha, “[...] não existe uma recomendação normativa nem catálogos de livros didáticos selecionados ou sugeridos pelas administrações educativas" (p. 39). São as próprias editoras que submetem os manuais às avaliações dos docentes, que irão decidir se utilizarão ou não as obras. No Chile, o livro didático "[...] é um suporte imprescindível do professor e é considerado como tendo uma função pedagógica importante” (p. 30), já que ele acaba sendo um dos materiais mais utilizados em sala de aula, inclusive é concebido como "[...] material de apoio necessário para a implementação do currículo ou de ajuste curricular” (p. 30).

As autoras também comentam que, nos três países, é crescente a preocupação com as novas tecnologias e com os suportes didáticos que as incluam, mas também ressaltam que "[...] a mera existência de recursos educativos digitais não é uma garantia de que cheguem à sala ou mesmo que seu aproveitamento pedagógico seja ótimo” (p. 44). Algumas dessas e outras questões são pontuadas nesse capítulo a partir de uma observação inicial das autoras; entretanto, nem todas elas são analisadas mais a fundo, mas nos instigam a pensar sobre várias questões que estão relacionadas ao livro didático, tais como a relação com o mercado editorial, currículo, usos pelos professores, relação desses materiais com os alunos e familiares, materiais paradidáticos, dentre outras.

No terceiro capítulo, Os livros didáticos de História: pesquisas atuais e critérios para sua análise e avaliação, Rafael Valls revisa a literatura sobre o tema, realizando uma perspectiva histórica sobre a diversidade de abordagens analíticas para livros didáticos. Valls centra sua análise nos livros

Práxis Educativa, Ponta Grossa, v. 11, n. 2, p. 526-530, maio/ago. 2016 Disponível em: <http://www.revistas2.uepg.br/index.php/praxiseducativa $>$ 
didáticos de ensino médio na Espanha, chamando a atenção para o fato de que, no caso espanhol, não há agências ou instituições administrativas oficiais que se encarreguem pela análise e pela avaliação dos livros didáticos. Nesse sentido, ele caracteriza esses manuais escolares e discute sobre a relação das editoras e os interesses e as escolhas dos professores.

Em seguida, o autor apresenta e avalia três modelos de análise do livro didático que surgiram em meados da década de 1990 pela Europa: a proposta de Weinbrenner (1992), de Selander (1995) e de Rüsen (1997). A partir disso, com base nesses modelos e frente às atuais problemáticas do contexto espanhol, ele propõe critérios para analisar e julgar os livros didáticos de História, sugerindo uma proposta sintetizadora dessas três, que possa se adequar à formação inicial dos docentes. Essa proposta colocada por Valls é pensada nos professores, que são os que avaliam e selecionam os livros didáticos na Espanha. Assim sendo, ele pontua e explica de uma maneira sintética alguns aspectos que devem ser contemplados para uma análise crítica dos manuais didáticos que contribua para superar os problemas e os desafios pontuados por ele no artigo a respeito da avaliação e da seleção de manuais didáticos espanhóis.

Laura H. Lima Muñiz, em Avaliação dos Livros Didáticos para o ensino secundário: caso México, descreve o processo de avaliação e de seleção dos livros didáticos ao que corresponde ao Ensino Médio no Brasil, explicando todas as etapas por quais esses livros passam, e quais são os critérios avaliativos e as normas exigidas pela legislação estatal para garantir a qualidade dos manuais didáticos. Em seguida, ela realiza um balanço dos livros didáticos submetidos à avaliação entre 2008 e 2009, destacando os principais acertos e as principais dificuldades desses materiais para o uso nas escolas. Por fim, Muñiz avalia alguns dados obtidos por meio de um questionário aplicado aos professores sobre o uso do livro didático de História, em que se percebeu, dentre outros elementos, que "[...] o livro didático continua sendo a coluna vertebral das aulas de história como fonte de informação" (p. 90). Com base nessas informações, a autora encerra o artigo pontuando algumas características gerais do que ela entende que seria um livro didático ideal.

No quinto capítulo, O processo de seleção de livros para as bibliotecas escolares e as bibliotecas de sala de aula no México, María Luisa Díaz González caracteriza as Bibliotecas Escolares e as Bibliotecas de Sala de Aula que são espaços destinados à valorização e ao estímulo à leitura, servindo também como material complementar e paradidático às disciplinas específicas. A autora apresenta um perfil dos leitores com diferentes níveis de leitura, que variam da pré-escola ao ensino secundário, e da literatura disponível, destacando e descrevendo o gênero e a categoria dessas coleções que compõem as bibliotecas. A autora também explica detalhadamente o processo de avaliação e de seleção dos livros destinados a essas bibliotecas.

Por fim, em Processo de certificação dos manuais escolares de história do $3^{\circ}$ ciclo do ensino básico em Portugal (2006 - 2010), Luís Alberto Marques Alves descreve a legislação que dá suporte à análise de livros didáticos em Portugal e explica o processo de avaliação e de seleção desses livros. Em seguida, o autor realiza um inventário dos 25 livros didáticos de História certificados em 2009, destacando aspectos positivos e negativos no "[...] rigor científico, linguístico e conceitual", na "[...] adequação ao desenvolvimento das competências definidas no Currículo Nacional" e na "[...] qualidade pedagógica e didática, designadamente no respeitante ao método, à organização, à informação e à comunicação" (p. 142). Para isso, conforme explicita o autor, foi selecionado, para cada ano e cada item, parte dos relatórios (documentos que contêm as análises dos manuais que estão em processo de certificação) que lhes pareceram mais ilustrativos do processo português. Procurando, assim, dar uma pequena mas significativa ideia “[...] sobre o teor dos relatórios, o tipo de enfoques privilegiados, o discurso utilizado, não sendo importante a identificação do manual" (p. 142).

Práxis Educativa, Ponta Grossa, v. 11, n. 2, p. 526-530, maio/ago. 2016 Disponível em: <http://www.revistas2.uepg.br/index.php/praxiseducativa $>$ 
Em vários países o livro didático é o material mais utilizado em sala de aula pelos professores de História, tendo uma importância pedagógica bastante acentuada. Portanto, pensar no livro didático requer entender as complexas relações que o envolvem. As discussões e os apontamentos levantados nessa coletânea de artigos permitem-nos conhecer os avanços e as dificuldades do processo de avaliação, de seleção e de distribuição desses livros em cada um dos seis países envolvidos, possibilitando-nos comparar essas diferentes realidades e contextos além de nos instigar a pensar em outras questões que estão envolvidas na relação entre livro didático e políticas públicas.

A troca de experiências possibilitada pela obra permite-nos reavaliar os nossos avanços, as nossas dificuldades e os nossos problemas a superar neste complexo processo que envolve, dentre ouras coisas, o mercado editorial e seus interesses econômicos, as políticas estatais, as relações historiográficas e didáticas, a reafirmação da valorização das pesquisas de ensino de História e livro didático. Enfim, essas e outras discussões provocadas pelo livro Para que $(\mathrm{m}) \mathrm{se}$ avalia? Livros didáticos e avaliações ajudam a guiar-nos na construção do tão sonhado livro didático ideal, convidando-nos a voltar nossos olhares de maneira mais cautelosa e atenciosa aos manuais didáticos, percebendo-os como instrumentos importantes para as questões que envolvem o ensino de História. 